\title{
Giant chorioangioma of placenta: a rare placental cause of polyhydramnios
}

\author{
Suneetha Allanki $^{1 *}$, Neethi Mala Mekala1, Sunethri Padma ${ }^{2}$
}

\begin{abstract}
${ }^{1}$ Department of Obstetrics and Gynecology, Government Medical College and Hospital, Nizamabad district, Telangana, India

${ }^{2}$ Department of Pathology, Gandhi Medical College, Secunderabad, Telangana, India
\end{abstract}

Received: 18 October 2018

Accepted: 19 December 2018

\author{
*Correspondence: \\ Dr. Suneetha Allanki, \\ E-mail: drallanki@yahoo.co.in
}

Copyright: (c) the author(s), publisher and licensee Medip Academy. This is an open-access article distributed under the terms of the Creative Commons Attribution Non-Commercial License, which permits unrestricted non-commercial use, distribution, and reproduction in any medium, provided the original work is properly cited.

\begin{abstract}
Chorioangioma belongs to benign nontrophoblastic primary vascular neoplasms of placenta, originating from primitive chorionic mesenchyme and has a cited prevalence of around $0.6 \%$ to $1 \%$ of all pregnancies. Though majority of them are asymptomatic, clinical course depends mainly on the size of the neoplasm. Giant chorioangiomas $(>4-5$ centimetres in diameter) with an approximate prevalence of around one in 9000 to one in 50,000 pregnancies, have been associated with many adverse maternal and fetal complications. We report a case of 21 -year-old primigravida lady, who presented to us at 37 weeks 4 days period of gestation with backache and with clinically evident increased liquor. On evaluating the cause of her polyhydramnios, ultrasonography revealed a well-defined echogenic vascular mass measuring $\sim 8 \mathrm{x} 8$ centimetres in the placenta, suggestive of chorioangioma. Though the condition is infrequent, through this case report, we emphasize that even placental factors need to be ruled out in evaluating causes of polyhydramnios. Despite large size of chorioangioma and associated hydramnios, our patient exceptionally didn't have any fetal complications. With proper antenatal surveillance, optimal feto-maternal outcome can be expected as seen in our case.
\end{abstract}

Keywords: Chorioangioma, Maternal and fetal complications, Placenta, Polyhydramnios, Ultrasonography, Vascular tumor

\section{INTRODUCTION}

Polyhydramnios, a state of pregnancy characterised by increased volume of amniotic fluid, is associated with several maternal and fetal complications with poor pregnancy outcomes. It has a cited prevalence ranging from 0.2 to $1.6 \%$ of all pregnancies. ${ }^{1,2}$ Despite having varied aetiology, it is considered to be idiopathic (50\%$60 \%$ ) in majority of cases. ${ }^{3} \mathrm{We}$ are reporting this case as chorioangioma is one of the rare placental causes of polyhydramnios. Chorangioma (also referred to as placental haemangioma) is a commonest biologically indolent benign neoplasm of placenta, characterized by the abnormal proliferation of vessels arising from chorionic tissue. It has a cited prevalence of around $0.6 \%$ to $1 \%$ of all pregnancies. They are commonly found in association with elderly primipara, twin pregnancies, hypertension and diabetes. Though majority of them are asymptomatic, clinical course depends mainly on the size of the neoplasm. Giant chorioangiomas ( $>4-5$ centimetres in diameter) with an approximate prevalence of around one in 9000 to one in 50,000 pregnancies, have been associated with many adverse maternal and fetal complications. ${ }^{4,5}$

\section{CASE REPORT}

A 21-year-old primigravida lady presented to our labor room (Department of Obstetrics and Gynaecology, Government general hospital, Nizamabad district) at 37 weeks 4 days period of gestation, with complaints of 
backache since one day and overdistension of abdomen since one week. On clinical examination, patient is short statured with height of $142 \mathrm{cms}$, vital data was normal and on obstetric examination, the presentation was breech with clinically apparent increased liquor.

Per-speculum and per vaginal examination findings are not suggestive of infection or labor. She had her antenatal visits at a regional hospital, her last antenatal ultrasonography (USG) done at 26 weeks was normal with fetal growth corresponding to period of gestation, with no evidence of fetal congenital malformations and with placenta in upper segment and adequate amount of liquor. Her previous blood pressures and blood sugars were within normal limits.

Patient was admitted for evaluation of polyhydramnios. Nonstress test was reactive. Blood sugars were tested and found to be normal. Infection screen was negative. Inpatient USG revealed polyhydramnios with amniotic fluid index (AFI) of 24- 26, with no obvious evidence of fetal structural malformations and fetal growth corresponding to period of gestation.

Placenta was located in the anterior wall of upper uterine segment, grade ш. Umbilical cord was trivascular. Around 8 x6 cms, single well-defined echogenic area, whose echogenicity was different compared to rest of the placenta, was noted on the fetal side of placenta as shown in Figure 1.

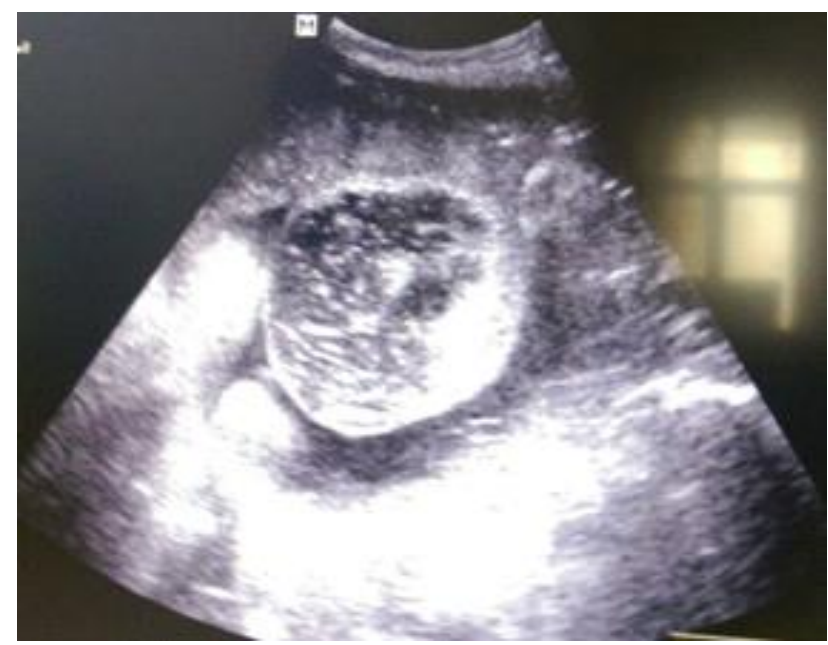

Figure 1: A gray scale ultrasound image representing well defined echogenic mass $\sim 8 \times 6 \mathrm{~cm}$ protruding from fetal side of placenta into the amniotic cavity.

Doppler scan demonstrated vascularity of the mass through a single vascular pedicle with similar flow rates as that of in umbilical cord and the features were more suggestive of placental chorioanioma. Steroid cover with betamethasone was given. USG repeated at 37 weeks 6 days of gestation in view of progressive abdominal overdistenstion revealed further increased quantity of liquor with $\mathrm{AFI} \sim 28-30$. Category-3 caesarean section was done at 38 weeks gestation in view of short statured primigravida with breech presentation and with increasing polyhydramnios to avoid further maternal and fetal complications.

A female baby weighing 2700 grams, with Apgar scores of 8 and 9 (at 1 and 5 minutes respectively) was delivered. Intraoperatively, liquor was clear and excess.

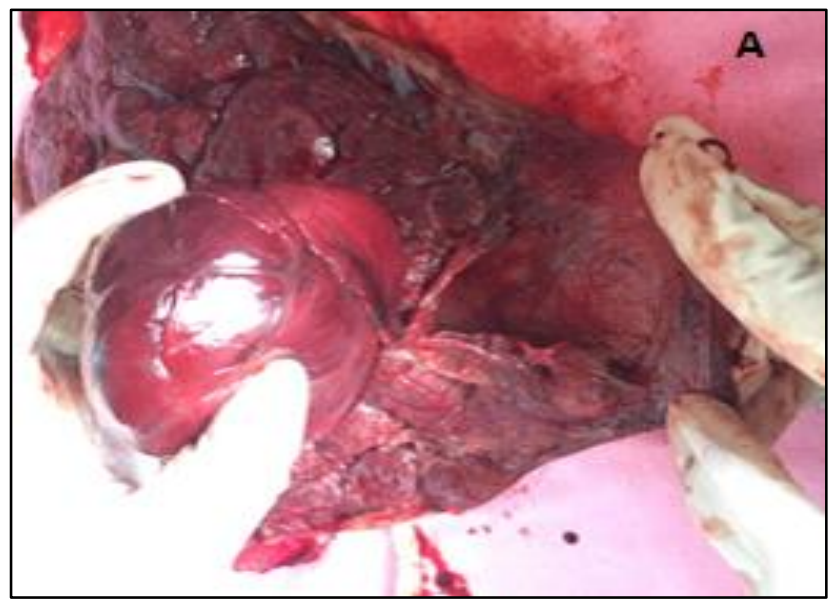

Figure 2A: Marginal location of placental chorioangioma uncovered by fetal membranes.

Placenta was located in the upper segment anteriorly and was delivered completely. Measures were taken to avoid postpartum haemorrhage. Placenta weighed 3 kilograms with an eccentric, well defined globular mass measuring $10 \times 8 \mathrm{cms}$ seen attached to its fetal surface with a vascular pedicle as shown in Figure 2A and 2B.

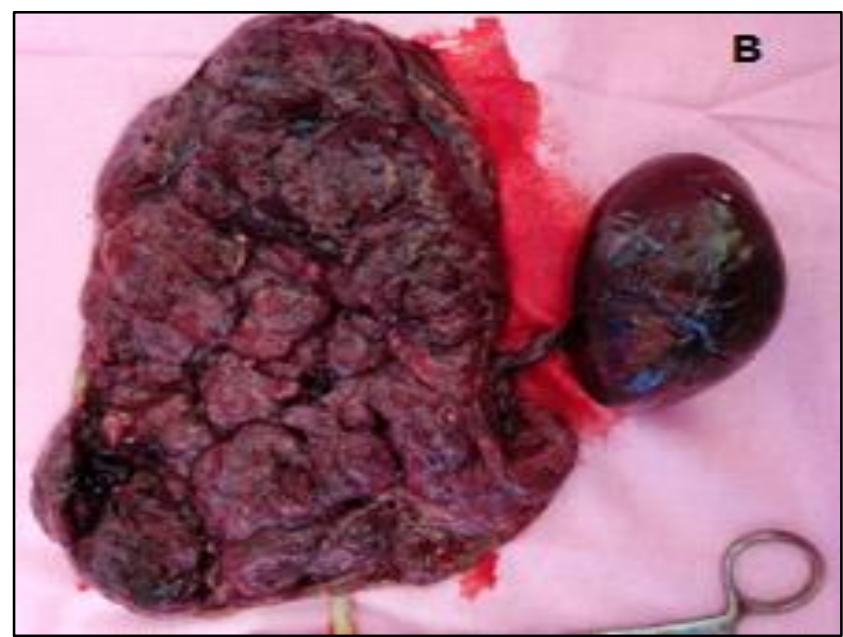

Figure 2B: A single large globular hyper vascular mass $\sim 10 \times 8 \mathrm{~cm}$, seen attached to placenta with a single vascular pedicle.

Histopathology confirmed the diagnosis of chorioangioma which was of angiomatous pattern (Figure 3). Postoperative period was uneventful. On follow up, both mother and baby were in good health. 


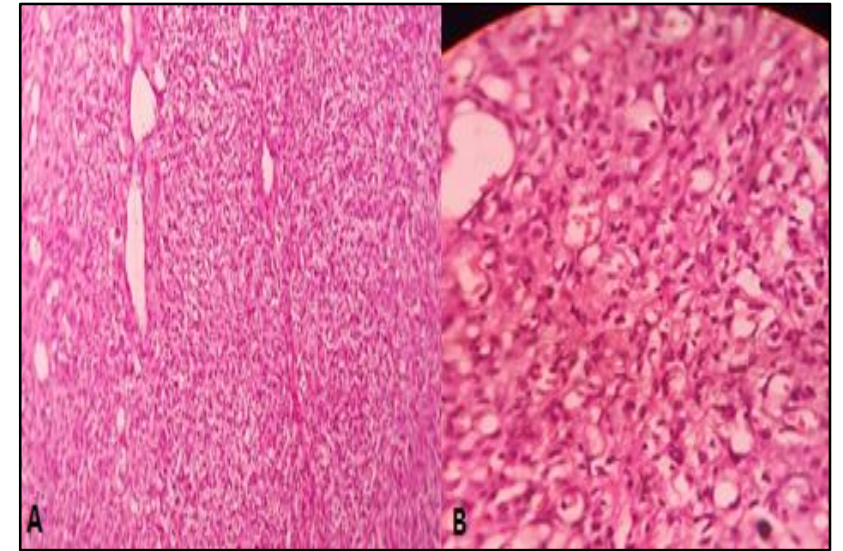

Figure 3: A-low power view of $\mathrm{H}$ and $\mathrm{E}$ stained section showing numerous proliferating capillaries lined by endothelium; B-high power view of $\mathbf{H}$ and $\mathbf{E}$ stained section showing small blood vessels lined by endothelium.

\section{DISCUSSION}

Polyhydramnios is usually defined as amniotic fluid index (AFI) $>25 \mathrm{~cm}$ and or largest fluid pocket depth (maximal vertical pocket (MVP) greater than $8 \mathrm{~cm}$ on USG. Aetiology and severity of hydramnios will determine the prognosis. Despite many identifiable causes, placental tumor as a cause of polyhrdramnios, though rare, is well documented in literature. ${ }^{4-6}$ In the described case, chorioangioma was serendipitously diagnosed while searching for causes of hydramnios.

\section{Pathology}

Chorioangioma, also known as placental hemangioma, initially reported in 1798, by John Clarke, is the most frequent benign non-trophoblastic primary vascular neoplasms of placenta, originating from primitive chorionic mesenchyme. ${ }^{7,8}$ They are found in around 0.6 to $1 \%$ of all pregnancies. ${ }^{9}$ Marchetti described three patterns of chorioangioma (angiomatous, cellular, degenerate), the most common being the angiomatous type. ${ }^{10}$ They have got no potentiality to transform to malignancy. Though chorioangiomas are assumed to arise by 16th day post fertilization, there are no such reports of neoplasm in first trimester, documented so far. ${ }^{11}$

\section{Clinical significance}

Though majority of chorioangiomas are asymptomatic, the size of the neoplasm is the major factor predicting the clinical course. Giant chorioangiomas ( $>4-5 \mathrm{cms}$ in diameter) with an approximate prevalence of around one in 9000 to one in 50,000 pregnancies, have been associated with many adverse maternal and fetal complications. ${ }^{4-6,8}$ Maternal complications include polyhydramnios (observed in many cases of chorioangiomas), preeclampsia, antepartum haemorrhage (resulting from either placental abruption or from rupture of vascular pedicle of tumor). Polyhydramnios can increase the risk of malpresentation, cervical incompetence, preterm labor, abruption of placenta as a result of sudden fall of intrauterine pressure secondary to rupture of membranes and is associated with increased risk of caesarean sections.

The mechanisms by which chorioangioma leads to formation of polyhydramnios remains elusive. Various theories described to explain the formation of polyhydramnios include:

- Tumor located near the cord insertion may result in obstruction to the blood flow, which further raises intravascular pressure resulting in increased transudation into the amniotic cavity.

- Increased transudation may also result from larger surface area of the prominent vessels of tumor.

- Shunting of the fetal blood into vascular channels of tumor may result in partial placental insufficiency leading to polyhydramnios. ${ }^{12}$

Fetal complications include anemia, growth restriction, hyperdynamic circulation, hydrops, fetal congestive cardiac failure, all of which contribute to high perinatal mortality rates of $\sim 30 \%$ to $40 \%$ associated with this condition. Arteriovenous shunts in large tumors attribute to increased cardiac venous return, impairing fetal circulation and thereby leading to cardiac failure..$^{4-6}$

Complications related to labor include abruption, cord prolapse, fetal distress secondary to rupture of membranes in polyhydramnios, postpartum haemorrhage, retained placenta, sepsis etc.

\section{Management}

Doppler ultrasonography is preferred for diagnosis of placental hemangiomas during antenatal period and they not only estimate the degree of vascularity of neoplasm but also helps in differentiating it from other lesions such as hematoma, placental teratoma, partial mole (have diffuse flow patterns), degenerated myoma (seen on the maternal surface). Gray scale features observed in majority of chorioangiomas include single, well circumscribed heterogenous mass different from rest of the placental tissue, often protruding into amniotic cavity, located usually near the umbilical cord insertion. The pulsatile flow in the feeding vessels of chorioangiomas, show same flow rates as that of in umbilical cord. Echopattern with time remains the same in case of chorioangioma, while that of a blood clot differs with time. ${ }^{13}$ Magnetic resonance imaging (MRI) is helpful in cases where it is difficult to differentiate neoplasm from myoma on USG. Final diagnosis is established by histopathological examination of placenta.

Management of chorioangioma is usually conservative. Asymptomatic cases are monitored by antenatal USG which is not only useful for close fetal monitoring but also for timely intervention in case of any complications. 
Different interventions (with varying success rates) used in treatment of chorioangiomas with complications include fetoscopic laser coagulation of vessels perfusing the neoplasm, endoscopic surgical devascularisation, chemosclerosis with absolute alcohol. ${ }^{4,14}$ Polyhydramnios can be managed by therapeutic amniocentesis and by use of prostaglandin synthetase inhibitors.

Exceptionally there were no fetal complications despite large size of neoplasm. In our case, we assume that the eccentric attachment of the tumor and relatively normal functioning of the remaining normal placental tissue could have maintained the fetal needs.

\section{CONCLUSION}

It is noteworthy that even placental factors need to be ruled out in evaluating causes of polyhydramnios and that not all giant chorioangiomas are associated with adverse maternal and fetal outcomes. Since there is a risk of poor perinatal outcome, we suggest thorough evaluation and proper maternal and fetal surveillance, as done in our case, for early detection of fetal distress and timely intervention, henceforth avoiding further complications and for optimum outcome. All placentas need to be sent for pathological examination, for confirmation of the diagnosis, whenever there is a diagnostic dilemma.

Funding: No funding sources Conflict of interest: None declared

Ethical approval: Not required

\section{REFERENCES}

1. Dashe JS, McIntire DD, Ramus RM, Santos-Ramos R, Twickler DM. Hydramnios: anomaly prevalence and sonographic detection. Obstet Gynecol. 2002;100(1):134.

2. Alexander E S, Spitz H B, Clark R A. Sonography of polyhydramnios. AJR Am J Roentgenol. 1982;138(2):343.

3. Golan A, Wolman I, Sagi J, Yovel I, David MP. Persistence of polyhydramnios during pregnancy - its significance and correlation with maternal and fetal complications. Gynecol Obstet Invest. 1994;37(1):18.
4. Haak MC, Oosterhof H, Mouw R. Pathophysiology and treatment of fetal anemia due to placental chorangioma. Ultrasound Obstet Gynecol. 1999;14(1):68-70.

5. Barros A, Freitas AC, Cabral AJ, Camacho MC, Costa E, Leitao $\mathrm{H}$ et al. Giant placental chorioangioma: a rare cause of fetal hydrops. BMJ Case Reports. 2011;02:3880.

6. Dhar H. Giant placental chorioangioma with intrauterine fetal death. JNMA. 2013;52(190):384-87.

7. Clarke J. Account of a tumour found in the substance of the human placenta. Philos Trans R Soc. 1798;88:361.

8. Fox H, Sebire NJ. Non-trophoblastic tumors of the placenta. In Pathology of the Placenta (3rd edn), Fox H, Sebire N (eds). Saunders Elsevier: Philadelphia, 2007;401-430.

9. Kuhnel P. Placental chorioangioma Acta Obstetricia et Gynecologica Scandinavica, vol. 13, pp. 143-145, 1933.

10. Marchetti AA. A consideration of certain types of benign tumors of the placenta. Surg Gynecol Obstet. 1939;68:733-43.

11. Bracero LA, Davidian M, Cassidy S. Chorioangioma: diffuse angiomatous form. Chorioangioma. 1993;9:18-1.

12. Kirkpatrick AD, Podberesky DJ, Gray AE, McDermott JH. Best cases from the AFIP: Placental chorioangioma. Radiograph. 2007;27(4):1187-90.

13. Zalel Y, Gamzu R, Weiss Y, Schiff E, Shalmon B, Dolizky M. Role of Color Doppler Imaging in Diagnosing and managing pregnancies complicated by Placental chorioangioma. J Clin Ultrasound 2002; 30(5):264-9.

14. Wanapirak C, Tongsong $\mathrm{T}$, Sirichotiyakul S, Chanprapaph P. Alcoholization: the choice of intrauterine treatment for chorioangioma. Journal of Obstet Gynaecol Res. 2002;28(2):71-5.

Cite this article as: Allanki S, Mekala NM,

Padma S. Giant chorioangioma of placenta: a rare placental cause of polyhydramnios. Int J Reprod Contracept Obstet Gynecol 2019;8:321-4. 